\title{
Temperature Dependence of Elastic Constants of Some Cermet Specimens ${ }^{1}$
}

\author{
Sam Spinner
}

(June 16, 1960)

\begin{abstract}
The temperature dependence of both Young's and shear modulus of four types of cermet specimens, known as "nickel-bonded titanium carbide," as well as $\mathrm{Ni}$ and TiC have been determined by a dynamic resonance method.

The Young's modulus temperature curves of the cermets are characterized by a linear decrease from room temperature until about 700 to $1,000{ }^{\circ} \mathrm{C}$. In this upper temperature region, an inflection in the relation develops, accompanied by an increase in internal friction. Both these effects are attributed to viscous grain boundary slip.

For shear modulus, only the linear portion of the modulus temperature relation was obtained. In this linear region, the relative decrease in shear modulus for the cermet specimens is greater than the relative decrease in Young's modulus for the same type of specimen. This means that Poisson's ratio rises with temperature for the cermets.
\end{abstract}

\section{Introduction}

Among the more noteworthy properties of cermets in general are their high values of elastic moduli. Although the literature dealing with the properties of cermets devotes considerable attention to their elastic constants $[1,2,3],{ }^{2}$ comparatively little attention has been paid to the values of these constants at elevated temperatures. ${ }^{3}$

Inasmuch as these cermets are intended to be used as structural members at elevated temperatures, and inasmuch as these studies $[4,5]$ have shown that their elastic moduli may decrease by as much as 15 percent at around $1,000{ }^{\circ} \mathrm{C}$ from their room temperature values, and may decrease by another 20 percent in the next $200{ }^{\circ} \mathrm{C}$ or so, it would appear that further data concerning the variation of these elastic constants with temperature would be most useful. The main purpose of this paper is to present such data. Furthermore, since the four types of cermets selected for obtaining these data are composed basically of the same constituents, varying from each other mainly in the relative proportions of metal and ceramic, comparison of the results among these types presents interesting possibilities for analysis.

\section{Experimental Procedures}

\subsection{Specimens}

The cermet specimens used in this investigation are known as "nickel-bonded titanium carbide". They were taken from among those used by Lang [1] for his room temperature measurements. These

\footnotetext{
1 This investigation was carried on under the sponsorship of the Division of Research, U.S. Atomic Energy Commission.

Figures in brackets indicate the literature references at the end of this paper 3 A paper by Watchman and Lam [4] containing one curve of Young's modulus as a function of temperature for one of the types of cermets used in this study, and a W ADC report [5] showing Young's modulus temperature curves on several cermet materials are the only data along these lines known to the author.
}

specimens were all in the shape of rectangular bars about 6 in. by $\frac{1}{2}$ in. by $\frac{1}{4}$ in. Table 1 , which gives the number of sets of determinations for both Young's and shear modulus performed on all of the specimens, retains Lang's scheme for identifying the cermet specimens as well as the manufacturer's designation. The table also includes the nominal metal content by weight of each type of cermet; the remainder (of each type) consisting of a solid solution composed of $\mathrm{TiC}$ and 8 percent of specimen weight of $(\mathrm{TiC}+\mathrm{NbC}+\mathrm{TaC})$. A description of the composition and microstructure of many types of cermets including some used in this investigation is contained in a report by Shevlin et al. [6]. The TiC and nickel specimens, which are included for comparison, are polycrystalline materials of commercial purity. The TiC specimen was cylindrical in shape, about 6 in. long and $\frac{1}{2}$ in. in diameter. The nickel specimen was about $7 \mathrm{in}$. long and $\frac{1}{2} \mathrm{in}$. square in cross section.

TABLE 1. Designation and number of determinations made on all specimens

\begin{tabular}{|c|c|c|c|c|}
\hline \multicolumn{2}{|c|}{ Specimens } & \multirow{2}{*}{$\begin{array}{c}\text { Nominal } \\
\text { metal } \\
\text { content }\end{array}$} & \multirow{2}{*}{$\begin{array}{l}\text { Number of } \\
\text { sets of } \\
\text { Young's } \\
\text { modulus } \\
\text { determina- } \\
\text { tions }\end{array}$} & \multirow{2}{*}{$\begin{array}{l}\text { Number of } \\
\text { sets of shear } \\
\text { modulus } \\
\text { determina- } \\
\text { tions }\end{array}$} \\
\hline M'frs. designation & $\begin{array}{l}\text { Lang's desig- } \\
\text { nation }\end{array}$ & & & \\
\hline $\mathrm{K}-150 \mathrm{~B}$ & $\left\{\begin{array}{r}\text { a } 31-1 \\
31-4\end{array}\right.$ & $\{10 \% \mathrm{Ni}$ & $\begin{array}{l}6 \\
3\end{array}$ & $\begin{array}{l}2 \\
3\end{array}$ \\
\hline K-151 B $\ldots$ & $\begin{array}{l}32-1 \\
32-2\end{array}$ & \}$_{20 \% \mathrm{Ni}}$ & $\begin{array}{l}1 \\
2\end{array}$ & $\overline{2}$ \\
\hline K-152 B .. & $\begin{array}{r}33-1 \\
33-10\end{array}$ & $30 \% \mathrm{Ni}$ & $\begin{array}{l}1 \\
2\end{array}$ & $-\overline{2}$ \\
\hline K-162 B & $34-1$ & $\left\{\begin{array}{l}25 \% \mathrm{Ni} \\
5 \% \mathrm{Mo}\end{array}\right.$ & 3 & $\begin{array}{c}1 \\
--\end{array}$ \\
\hline $\begin{array}{l}\text { Titanium Carbide } \\
\text { Nickel. }\end{array}$ & & & $\begin{array}{l}5 \\
3\end{array}$ & - \\
\hline
\end{tabular}

a The number preceding the dash indicates the type of cermet and corresponds to the manufacturer's designation. The number following the dash indicates the particular specimen. 


\subsection{Method and Calculations}

The elastic moduli measurements at elevated temperatures were performed by a dynamic resonance method as described by Wachtman and Lam [4]. Essentially, the method consists of suspending the specimen in a furnace from two fibers, one fiber being attached to an electromagnetic driver and the other to a crystal pickup. The driver and pickup are outside the furnace and connected to appropriate electronic equipment for arousing and detecting the mechanical resonance frequencies of the specimen. The evidence of resonance is indicated by a Lissajou pattern on a cathode ray oscilloscope. The most satisfactory suspension elements were found to be molybdenum wires coated with nickel and chromium to prevent oxidation [7].

If the suspension wires are tied at opposite sides of the specimen, as shown in the sketch (fig. 1) from a previous paper [8], then, in addition to the usual flatwise flexural resonance vibrations, the edgewise flexural resonance vibrations and, even more important, the torsional resonance vibrations of the specimens can be detected. The response of one of the flexural resonance frequencies, usually the edgewise, usually died out at a lower temperature than the other. Also, because of the geometry of the specimens (the fairly low ratio of width to depth of the cross section) the response of the torsional resonance frequency was weaker than the flexural ones and died out at the lowest temperature.

Occasionally, the torsional response would disappear at one temperature and reappear at a higher one before dying out completely. 'The larger number of sets of Young's modulus-temperature determinations in table 1, as compared with the number of sets of shear modulus-temperature determinations, is mainly due to the fact that the experimental phase of the investigation of the cermet specimens had been about half completed before it was noticed that the torsional resonance vibrations could be detected at all. Nevertheless, at least one set of torsional resonance vibrations was obtained for each type of cermet. The flexural vibrations are related to Young's modulus while the torsional vibrations are

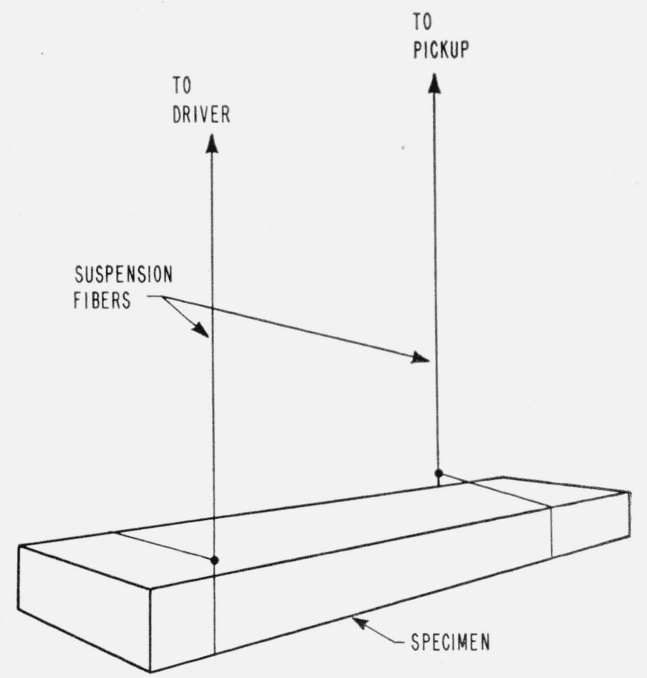

Figure 1. Method of suspending specimens for obtaining torsional as well as flexural vibrations.

related to the shear modulus. Because of the square and circular cross section of the $\mathrm{Ni}$ and $\mathrm{TiC}$ specimens, a satisfactory torsional mode could not be obtained at elevated temperatures, so that for these specimens only Young's modulus as a function of temperature could be determined.

The ratio of a particular elastic modulus at elevated temperature to the same modulus at room temperature, $E_{t} / E_{0}$, was calculated from the wellknown equation,

$$
\frac{E_{t}}{E_{0}}=\left(\frac{f_{t}}{f_{0}}\right)^{2} /\left(1+\frac{\Delta l}{l}\right)
$$

where $f_{t} / f_{0}$ is the ratio of the corresponding resonance frequencies.

The factor, $[1+(\Delta l / l)]$ is the correction for thermal expansion of the specimen from room temperature to the temperature of measurement. Values of $\Delta l / l$, the linear thermal expansion over the required temperature range, were obtained for the cermet specimens from dilatometer measurements. These data are shown in figure 2. Corresponding data for 'TiC

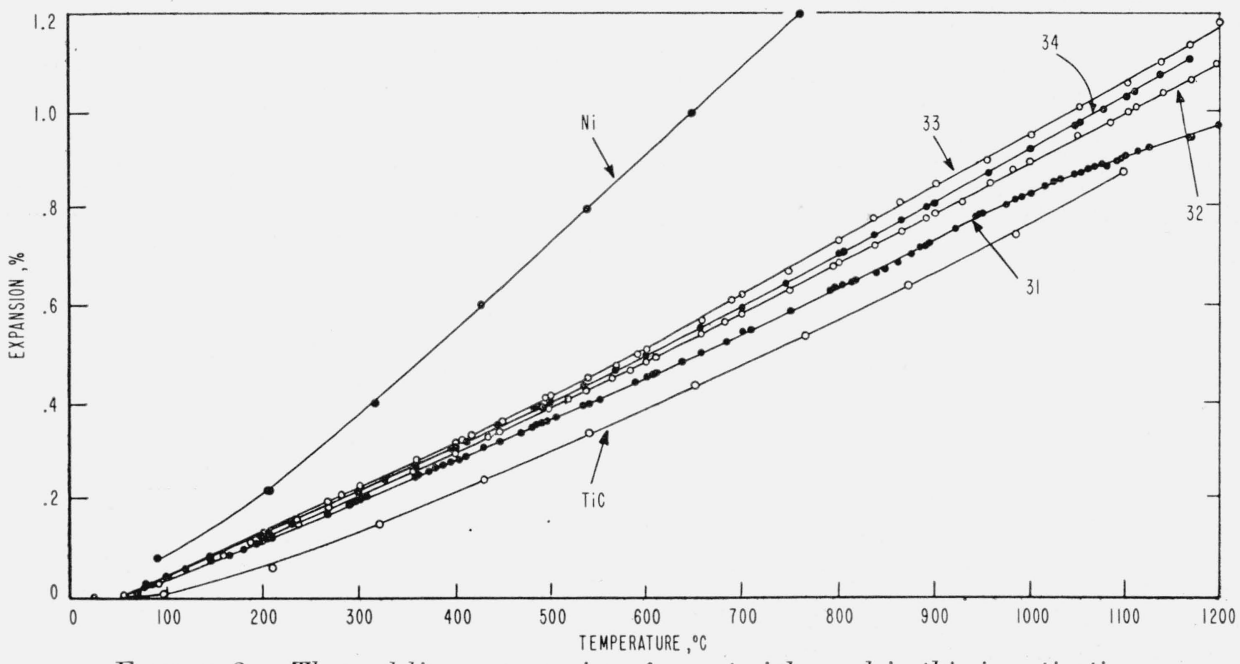

FIGURE 2. Thermal linear expansions for materials used in this investigation. 
and nickel were taken from the literature $[9,10,11]$. They are also included in figure 2 for comparison with the cermets.

Equation (1) makes no restriction as to the type of vibration frequencies involved in obtaining $E_{t} / E_{0}$ [12]. The conditions that must be fulfilled are that the specimens do not change in shape on heating and that $f_{t}$ and $f_{0}$, in a particular ratio, both represent the same type of vibration frequency, whether torsional, flexural flatwise or flexural edgewise. Thus, if $f_{t} / f_{0}$ are flatwise or edgewise flexural resonance frequencies, then $E_{t} / E_{0}$ becomes the ratio of Young's moduli, $Y_{t} / Y_{0}$, and if $f_{t} / f_{0}$ are torsional resonance frequencies, then $E_{t} / E_{0}$ becomes the ratio of the shear moduli, $G_{t} / G_{0}$. Equation (1) also holds if $f_{t} / f_{0}$ represent overtones of the fundamental of any type of vibration. However, in this study, the fundamental resonance frequencies were used almost entirely.

If more than one resonance frequency for calculating a particular elastic modulus is used, then the agreement in $E_{t} / E_{0}$ from these resonance frequencies provides an internal check on the consistency of the data. The agreement in $Y_{t} / Y_{0}$ from the two reso- nance flexural frequencies at any particular temperature at which both could be detected was on the order of 0.1 percent justifying the use of the average of these two values for that temperature. For the $G_{t} / G_{0}$ determinations, usually only one ratio of resonance frequencies was available for a particular point (under some unusually favorable conditions, the first overtone of torsion could be obtained and similarly averaged with the fumndamental), so that the agreement of repeated sets of determinations served as a measure of the precision of the data. Repeated sets of determinations were available in all but one case (table 1) for $G_{t} / G_{0}$. For $Y_{t} / Y_{0}$, a larger number of determinations was available in all cases. From these repeated measurements, it is estimated that the precision over the linear range of $Y_{t}$ is on the order of 0.3 percent and that of $G_{t}$ is about 0.4 percent. These repeated measurements, and consequently the above figures of precision, include the data for both specimens of each type (when two specimens were used), and no distinction is indicated in the notation in figures 3 and 4 between the two specimens of each type.

If $G_{t}$ as well as $Y_{t}$ are determined, then the speci-

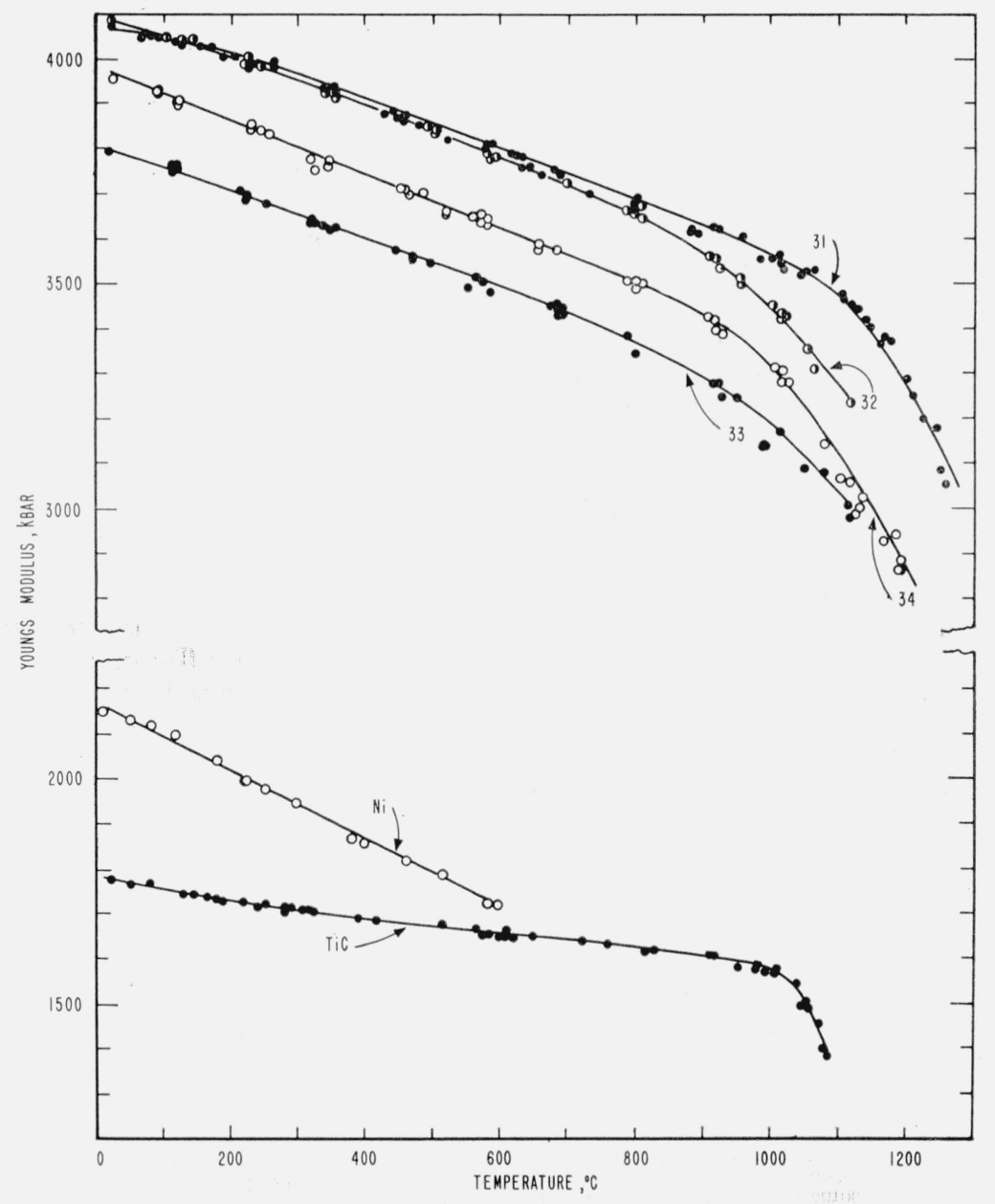

FIGURE 3. Young's modulus-temperature relations for the materials of this investigation. 


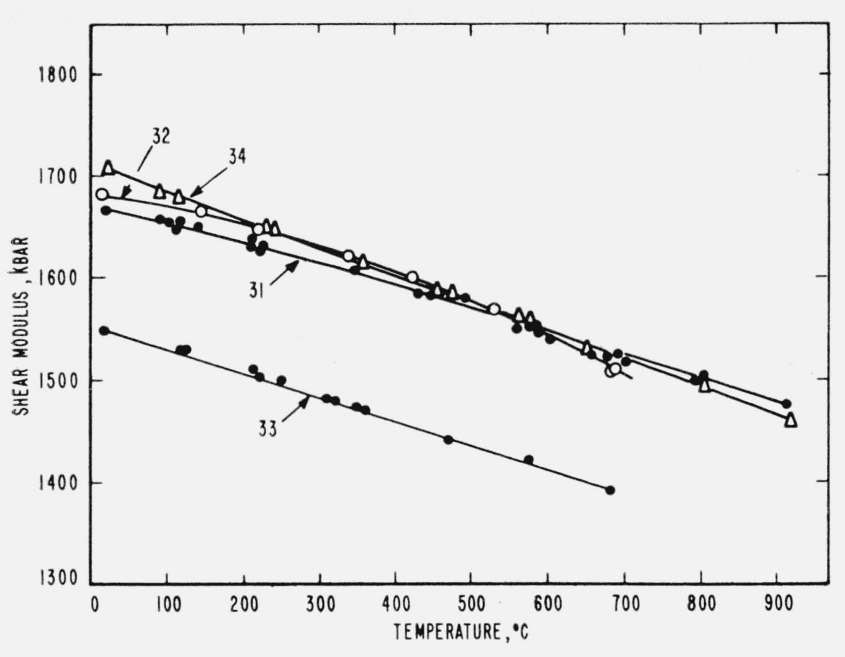

Figure 4. Shear modulus - temperature relations for the four types of cermets used in this study.

mens are completely specified elastically over the temperature range over which these two moduli can be measured, since, for isotropic materials ${ }^{4}$ all elastic constants are related by well-known equations in such a way that if any two are known the others can be determined. In this study Poisson's ratio, $\mu$, was computed from these two moduli.

In order to plot $Y_{t}$ and $G_{t}$ directly as a function of temperature, a room temperature or base value of both Young's and shear modulus, $Y_{0}$ and $G_{0}$ must be obtained. For the cermets, these values (of $Y_{0}$ and $G_{0}$ ) were obtained by averaging the values obtained by Lang[1] for the particular specimens of each type used. For TiC, $Y_{0}$ and $G_{0}$ were determined from the flexural and torsional resonance frequencies, respectively, the mass and the dimensions based on Pickett's relations [13]. The value for nickel was taken from the literature [14]. The values so obtained for all the types of specimens used are given in table 2. Since $\dot{Y}_{0}$ and $G_{0}$ are available for each type of specimen, Poisson's ratio, $\mu$, may also be calculated from the familiar relation,

$$
\mu=\frac{Y}{2 G}-1
$$

This is given in the final column of the table.

It should be noted that the choice of the base values, $Y_{0}$ and $G_{0}$, is not critical. Had different values of these moduli been chosen on the basis of some other reasonable selection, it would not have significantly changed the shape of the temperature modulus curves shown in figures 3 and 4 , but would only have caused a slight upward or downward displacement of these curves.

\footnotetext{
${ }_{4}$ The materials are considered to be isotropic because, although the individual grains of which they are composed are antisotropic, nevertheless their orientation and distribution are random, so that macroscopically this condition of isotropy is substantially fulfilled. Actually, some of Lang's[1] results indicated that some preferred crystal orientation or inhomogeneity might exist in the specimens. However, these departures from isotropy, if they exist at all, are small mens. However, these departures from isotropy, if they exist at all, are small
}

TABLE 2. Room temperature base values of specimens used in this investigation

\begin{tabular}{c|c|c|c}
\hline \hline $\begin{array}{c}\text { Specimen } \\
\text { type }\end{array}$ & $\begin{array}{c}\text { Young's mod- } \\
\text { ulus } Y_{0}\end{array}$ & $\begin{array}{c}\text { Shear modu- } \\
\text { lus } G_{0}\end{array}$ & $\begin{array}{c}\text { Poisson's } \\
\text { ratio } \mu\end{array}$ \\
\cline { 2 - 3 } & kilobars & kilobars & \\
31 & 4074 & 1669 & 0.220 \\
32 & 4077 & 1681 & .213 \\
33 & 3791 & 1550 & .223 \\
34 & 3952 & 1701 & .162 \\
$\mathrm{TiC}$ & 1774 & 748.9 & .184 \\
$\mathrm{Ni}$ & 2147 & - & \\
\hline
\end{tabular}

\subsection{Oxidation}

The specimens oxidized slightly at elevated temperatures. This oxidation was noted by a decrease in the resonance frequencies, as well as the usual change in surface appearance and increase in mass, after the specimens had been returned to room temperature, as compared with the original values. This irreversible decrease in resonance frequencies is superimposed on the reversible decrease associated with increased temperature in the course of a modulus-temperature determination. Table 3 gives typical data of such changes in mass and one of the resonance frequencies for some specimens before and after heating.

$\mathrm{T}_{\mathrm{ABLE}}$ 3. Typical changes in mass and a resonance frequency before and ofter heating

\begin{tabular}{|c|c|c|c|c|c|c|}
\hline \multirow{2}{*}{ Specimen } & \multicolumn{2}{|c|}{ Mass } & \multirow{2}{*}{${\frac{\mathrm{m}_{b}}{m_{a}}}^{1}$} & \multicolumn{2}{|c|}{$\begin{array}{l}\text { Resonance } \\
\text { frequency }\end{array}$} & \multirow{2}{*}{$\left(\frac{f_{a}}{f_{b}}\right)^{2}$} \\
\hline & $\begin{array}{c}\text { Before } \\
m_{b}\end{array}$ & $\begin{array}{c}\text { After } \\
m_{a}\end{array}$ & & $\begin{array}{c}\text { Before } \\
f_{b}\end{array}$ & $\underset{f_{a}}{\text { After }}$ & \\
\hline & $g$ & $g$ & & $c / s$ & $c / s$ & \\
\hline $\begin{array}{l}31-1- \\
32-1 \\
33-1 \\
34-1\end{array}$ & $\begin{array}{l}71.296 \\
77.205 \\
75.489 \\
73.960\end{array}$ & $\begin{array}{l}71.561 \\
77.370 \\
75.726 \\
74.015\end{array}$ & $\begin{array}{r}0.9963 \\
.9979 \\
.9969 \\
.9993\end{array}$ & $\begin{array}{l}2534 \\
2410 \\
2312 \\
2445\end{array}$ & $\begin{array}{l}2515 \\
2404 \\
2302 \\
2444\end{array}$ & $\begin{array}{r}0.9851 \\
.9950 \\
.9914 \\
.9992\end{array}$ \\
\hline
\end{tabular}

1 Ratio of mass before to mass after heating.

2 Square of ratios of fundamental flatwise flexural resonance frequencies before and after heating.

No significance can be given to the different changes for the different specimens inasmuch as they were not subjected to the same time-temperature schedules. It is seen that the largest increases in mass are associated with the largest decreases in resonance frequency. However, the decrease in resonance frequency cannot be accounted for completely by the increase in mass. In order for this condition to obtain the following relation would have to hold:

$$
\frac{m_{b}}{m_{a}}=\left(\frac{f_{a}}{f_{b}}\right)^{2}
$$

where $m$ is the mass; $f$ is a particular resonance frequency, and the subscripts $b$ and $a$ stand for "before" and "after" heating. Comparison of columns 4 and 7 of table 3 shows that the change in mass accounts for only a part of the change in resonance frequency. If the oxide only forms a 
coating over the main body of the specimen, as seems likely, this would account for the fact that $\left(f_{a} / f_{b}\right)^{2} \neq$ $m_{b} / m_{a}{ }^{5}$

It was first hoped that if a specimen was heated once or, if necessary, several times, an oxide coating would eventually form which would inhibit further oxidation, so that subsequent determinations on such specimens would require no correction for this phenomenon. Unfortunately, this did not occur. Successive heatings, especially if the times involved were not short, always resulted in some further oxidation.

Clearly, the most effective way to avoid oxidation would be to have the specimen in a vacuum or inert atmosphere during the measurements at elevated temperatures. An apparatus for making such measurements in vacuo is available and was used to obtain the data for the $\mathrm{TiC}$ specimen, in which the oxidation was more extensive than in the cermets. Wachtman and Lam [4] also used this same apparatus for their determination on the $\mathrm{K}-150 \mathrm{~B}$ cermet (No. 31). However, it was found more convenient to use the larger furnace in open atmosphere for the rest of the specimens, mainly because this larger furnace had smaller thermal gradients, and also because the torsional response could be obtained much more readily in the larger (air) furnace.

After a number of sets of determinations were made in this furnace in an air environment, the amount of further oxidation was considerably reduced by having the furnace flushed with nitrogen gas during a determination. The sets of determinations for the cermet specimens listed in table 1 include those made in ordinary and nitrogen flushed atmosphere.

The temperature-frequency relations were adjusted for the decrease due to oxidation by raising the recorded frequency at the highest temperature reached by multiplying by the factor, $f_{b} / f_{a}$, and linearly interpolating this increase from the highest temperature down to $800^{\circ} \mathrm{C}$. Below this temperature, it was established experimentally that no significant oxidation took place in the times ordinarily involved.

Also, since the oxide coating which a specimen took on on heating did not apparently affect its intrinsic elastic modulus nor its temperature dependence, the new lower values of $f_{0}$ after a particular heating could be used with the original values of $Y_{0}$ and $G_{0}$ in subsequent sets of determinations. This procedure appeared justified by the reproducibility of successive sets of determinations when it was adopted.

The nickel specimen did not oxidize sufficiently to require correction.

\section{Results}

\subsection{Grain Boundary Slip}

We consider first the Young's modulus temperature curves in figure 3 . The general pattern is seen to be an approximately linear decrease until a temperature around 800 to $1,000{ }^{\circ} \mathrm{C}$ in which region a sharper

${ }^{5}$ The changes in the resonance frequencies of the specimens on oxidation suggest the possibility of their utilization as a means of studying oxidation as a function of time and temperature in addition to the conventional methods (of changes in mass or gas pressure). decrease takes place. This inflection in the modulustemperature characteristic is attributed to grain boundary slip (henceforth designated by the initials g.b.s.). This phenomenon has been discussed by Zener [15] using data from polycrystalline metals and extended by Wachtman and Lam [4] to polycrystalline ceramics.

A qualitative explanation of what is believed to occur may be presented in the following way:

Until the temperature region of g.b.s. is reached, the grain boundaries do not contribute significantly to the elastic modulus, the main contribution arising from the elastic properties of the grains themselves. The "normal" linear decrease in modulus with temperature is due to the odd and even powered terms of the anhormonic expansion as described by Stern [16[. (The thermal expansion is due only to the odd powered terms of the same expansion.)

At some elevated temperature (which marks the onset of g.b.s.), viscous flow between grains adds a nonrecoverable, relaxed component to the purely elastic (unrelaxed) strains which were predominant up to this region. Consequently, there is a rapid decrease in the measured modulus, which is superimposed on the linear decrease that has taken place up to this temperature region. This process continues at a faster rate as the temperature rises and the effective viscosity decreases. Since this viscous movement between grains involves energy losses, the region of g.b.s. is characterized not only by a more rapid decrease in the measured modulus but also by an increase in internal friction $\left(Q^{-1}\right)$. The decrease in amplitude and sharpness of the resonance responses, indicative of this rise in $Q^{-1}$, did indeed take place and was chiefly responsible for the loss in precision in this region. In fact, this increase in $Q^{-1}$ is as much a feature of the region of g.b.s. as the inflection in the temperature-modulus characteristic. Had these inflections taken place without the concomitant increase in $Q^{-1}$, then some other mechanism would be required to explain them.

As the temperature continues to rise, the effective intergranular viscosity also continues to decrease so that the energy losses associated with g.b.s. should also decrease. This should eventually result in a decrease in $Q^{-1}$, though not to the level existing before the region of g.b.s. This should be evidenced by a partial restoration of the amplitude and sharpness of the resonance responses and also by a second inflection in the modulus temperature curve. This marks the end of the region of g.b.s. Zener [15] cites experimental evidence of this second inflection with metals.

However, no reliable evidence of having traversed the region of g.b.s. was found for any of the materials of this investigation, nor, for that matter, with any ceramic materials measured by the author, even when the temperature was raised more than $200{ }^{\circ} \mathrm{C}$ higher than that for which a final reliable resonance response could be detected. Wachtman and Lam's data also gives no evidence of having traversed the region of g.b.s. Two possible explanations which suggest themselves for this are that the region of g.b.s. covers a much wider temperature region than antic- 
ipated, or that, if the region is traversed, the improved response is not sufficient to be detected above the higher general noise level associated with the various mechanisms which are more likely at elevated temperatures.

The upper temperature limit of recorded elastic moduli was reached, then, when the responses became so diffuse and weak that they could not be distinguished from the general background noise and spurious responses which inevitably develop when it becomes necessary to drive the specimens harder and harder as the true responses become progressively weaker. For the nickel specimen this limit occurred when the modulus temperature relationship was still linear, as it did mainly for the torsional responses of the cermet specimens, shown in figure 4 .

The general characteristics of the modulus temperature curves as well as the recovery of sharpness and amplitude of the resonance responses are found to be reversible on cooling. Also, in the absence of oxidation, the specimens generally return to the same room temperature values of resonance frequency that they had originally, indicating no permanent average structural change due to g.b.s.

It is also noted from figure 2 that no noticeable corresponding inflection occurs in the thermal expansion curves around the temperature region in which the inflection associated with g.b.s. occurs in figure 3.

We now compare the types of specimens with respect to g.b.s. It is noted that for $\mathrm{TiC}$ the inflection indicating the start of this region comes at a higher temperature than for the cermets; and, once started, the modulus drops more sharply for $\mathrm{TiC}$ than for the cermets. The presence of the metal in the cermet has the effect of hastening the start of, and broadening the measurable region of g.b.s. The contribution of the nickel on this region in the cermets is difficult to evaluate since the responses for the nickel itself died out before g.b.s. developed. However, it seems reasonable that the presence of more than one type of grain boundary should result in a broadening of the g.b.s. region. The presence of two types of grains such as are present in the cermets results in three types of grain boundaries, $\mathrm{Ni}-\mathrm{Ni}$, carbide-carbide, and $\mathrm{Ni}$-carbide.

In general, if there are $n$ types of grains, and it is assumed that each grain forms a boundary either with another grain of the same type or with a different type of grain, then the number of types of grain boundaries will be given by $n(n+1) / 2$.

\subsection{Temperature Coefficient of Elastic Moduli}

'The relative decrease with temperature in Young's and shear modulus in the linear region, $-1 / Y_{0}(\Delta Y / \Delta t)$ and $-1 / G_{0}(\Delta G / \Delta t)$, and their standard deviations are given in table 4 . These values were computed from a least square solution of the numerical data on which figures 3 and 4 are based. The range of $\Delta t$ selected (and also given in the table) was as wide as possible to give representative values without entering into the inflection region marking the onset of g.b.s.
TABLE 4. Relative decrease in Young's and shear moduli over the linear range

\begin{tabular}{|c|c|c|c|c|}
\hline Specimen & $\begin{array}{l}-\frac{1}{Y_{0}}\left(\frac{\Delta Y}{\Delta t}\right)^{\mathrm{a}} \\
\times 10^{-5} \operatorname{per}^{\circ} \mathrm{C}\end{array}$ & $\Delta t$ b in ${ }^{\circ} \mathrm{C}$ & $\begin{array}{l}-\frac{1}{G_{0}}\left(\frac{\Delta G}{\Delta t}\right)^{\mathrm{c}} \\
\times 10^{-5} \text { per }^{\circ} \mathrm{C}\end{array}$ & $\Delta t$ b in ${ }^{\circ} \mathrm{C}$ \\
\hline $\begin{array}{l}\mathrm{TiC} \\
31 \\
32 \\
33 \\
34 \\
\mathrm{Ni}\end{array}$ & $\begin{array}{l}10.4 \pm 0.3 \mathrm{~d} \\
12.4 \pm .1 \\
13.3 \pm .2 \\
14.4 \pm .2 \\
14.5 \pm .1 \\
35.7 \pm .6\end{array}$ & $\begin{array}{l}950 \\
900 \\
800 \\
700 \\
800 \\
600\end{array}$ & $\begin{array}{l}13.2 \pm 0.3 \\
14.9 \pm .8 \\
15.9 \pm .3 \\
15.6 \pm .1\end{array}$ & $\begin{array}{l}900 \\
690 \\
675 \\
800\end{array}$ \\
\hline
\end{tabular}

a Relative decrease in Young's modulus.

b Temperature range from room temperature to value given

c Relative decrease in shear modulus.

d Standard deviation.

It is seen from table 4 that both $-1 / Y_{0}(\Delta Y / \Delta t)$ and $-1 / G_{0}(\Delta G / \Delta t)$ increase in absolute value with increasing metal content. TiC and $\mathrm{Ni}$ (for which only $-1 / Y_{0}(\Delta Y / \Delta t)$ are available) have the lowest and highest values of relative slope respectively, forming the "end members" in the foregoing pattern.

Cermets No. 33 and 34 , which have the same percent of metal content and vary from each other only in that one (No. 33) contains only nickel as the metal while the other (No. 34) contains 25 percent nickel and 5 percent molybdenum, show very little difference in $-1 / Y_{0}(\Delta \dot{Y} / \Delta t)$ and $-1 / G_{0}(\Delta G / \Delta t)$. From figure 2, it may also be seen that the specimens arrange themselves in the same order with respect to positive coefficients of thermal expansion, $1 / l_{0}(\Delta l / \Delta t)$ as they do for the negative temperature coefficients of elastic moduli; i.e., the steepest slopes for both these coefficients regardless of sign are associated with nickel and decrease in the same order for the remainder of the specimens.

\subsection{Titanium Carbide and Nickel}

The value of $Y_{0}$ obtained for the TiC specimen (given in table 3 ) is not definitive for $\mathrm{TiC}$ in general. First, the specimen is of commercial purity and small impurities present probably affect the measured value of $Y_{0}$ to some extent. Second, in the process of manufacture, TiC is often not produced in the proper stochiometric ratio [17]. This can also affect the value of $Y_{0}$. The third and most important factor affecting the value of $Y_{0}$ of the TiC specimen was that it was quite porous. Its density, as derived from the mass and volume, computed from its dimensions was $3.558 \mathrm{gm} / \mathrm{cm}^{3}$. Using the theoretical density of $4.938 \mathrm{gm} / \mathrm{cm}^{3}$ of Schwartzkopf [17] one calculates the porosity of the specimen to be 28 percent.

Mackenzie [18] has developed a theoretical relation showing how the elastic modulus increases as the porosity decreases. Coble and Kingery [19] have obtained experimental results in good agreement with Mackenzie's relation using $\mathrm{Al}_{2} \mathrm{O}_{3}$ specimens of different porosites. Using Mackenzie's relation, the $Y_{0}$ of the $\mathrm{TiC}$ specimen was estimated to be 3411 kilobars at theoretical density. One should also be cautioned here that the ceramic phase of the cermets is not "pure" TiC but a solid solution consisting of TiC and other carbides (sec. 2, 2.1, a). 
Coble and Kingery also showed in the paper just referred to that the relative slopes of the Young's modulus temperature curves, $-1 / Y_{0}(\Delta Y / \Delta t)$, in the linear region were essentially independent of the porosity of the specimens. If it is assumed that this also holds for TiC, then the value of $-1 / Y_{0}(\Delta Y / \Delta t)$ given in table 4 will not be affected. Incidentally, the relative changes in the elastic moduli may be computed directly from the primary data, $Y_{t} / Y_{0}$ or $G_{t} / G_{0}$, and are independent of the particular values selected for $Y_{0}$ or $G_{0}$.

The value of $-1 / Y_{0}(\Delta Y / \Delta t)$ obtained here for nickel $\left(3.6 \times 10^{-4}\right.$ per $\left.{ }^{\circ} \mathrm{C}\right)$ was in fairly good agreement, as far as could be determined from the graphs, with that obtained by Koster [19] for a cold worked unmagnetized specimen $\left(3.8 \times 10^{-4}\right.$ per $\left.{ }^{\circ} \mathrm{C}\right)$. Koster's range of $\Delta t$ was from -180 to $400{ }^{\circ} \mathrm{C}$, but $\Delta t$ selected for the value just given was from 20 to $400{ }^{\circ} \mathrm{C}$. Further data taken with this specimen were also in general agreement with those obtained by Koster for annealed specimens.

\subsection{Comparison of Relative Slopes of Young's and Shear Modulus}

Inspection of table 4 also shows for each type of specimen (where both values exist) that

$$
\left|\frac{1}{G_{0}}\left(\frac{\Delta G}{\Delta t}\right)\right|>\left|\frac{1}{Y_{0}}\left(\frac{\Delta Y}{\Delta t}\right)\right|
$$

This means that Poisson's ratio, $\mu$, increases with increasing temperature.

Individual values of $\mu$ calculated, from the numerical values of $Y_{t}$ and $G_{t}$ in all cases where both values existed, from eqn (2) confirmed this small but significant increase in $\mu$ with increasing temperature.

Coble and Kingery [19] also found Poisson's ratio to increase with temperature for $\mathrm{Al}_{2} \mathrm{O}_{3}$ as did Lang and Knudsen [20] using $\mathrm{ThO}_{2}+0.5$ percent $\mathrm{CaO}$ by weight.

Zener [15] has deduced from theoretical considerations that the relaxation associated with g.b.s. should cause the relative decrease in the measured value of $G$ to be three times that of $Y$. Unfortunately this result cannot be checked experimentally, not only because this region could not be observed for $G$, but also because the upper temperature region of g.b.s could not be determined for $Y$.

\section{Summary}

1. The temperature dependence of Young's modulus and shear modulus on four types of nickelbonded $\mathrm{TiC}$ specimens have been determined by a dynamic resonance method. Similar measurements have also been made on nickel and $\mathrm{TiC}$ for comparison.

2. The relative decrease in both Young's and shear modulus with temperature was in the following order with the material having the smallest relative decrease listed first: TiC, 10 percent nickel content cermet, 20 percent nickel, 30 percent nickel, and 25 percent nickel +5 percent molybdenum, and nickel.
3. The inflection in the Young's modulus temperature curves was attributed to grain boundary slip.

4. The relative decrease in shear modulus with temperature was greater than that for Young's modulus, where both values were known, for the same type of specimen. Therefore Poisson's ratio rises slightly with temperature.

The author is indebted to J. Pastine for performing a portion of the calculations on which figures 3 and 4 were based, and to H. S. Parker and S. M. Lang for making the thermal expansion measurements on the cermet specimens.

\section{References}

[1] S. M. Lang, Properties of high temperature ceramics and cermets elasticity and density at room temperature, NBS Mono. 6 (Mar. 1, 1960).

[2] M. J. Kerper, L. E. Mong; M. B. Stiefel, and S. F. Holley, Evaluation of tensile, compressive, torsional, transverse, and impact tests and correlation of results for brittle cermets, J. Research NBS 61149 (1958) RP 2895.

[3] J. W. Graham and J. C. Redmond, Cermets, in High Temperature Technology (I. E. Campbell, ed.) chap. 10, p208 (John Wiley \& Sons, Inc., New York, N.Y., 1956).

[4] J. B. Wachtman Jr. and D. G. Lam Jr., Young's modulus of various refractory materiais as a function of temperature, J. Am. Ceram. Soc. 42, [5] 254 (1959).

[5] E. J. Soxman, M. T. Curran, J. R. Tinklepaugh (from N.Y. State College of Ceramics, Alfred Univ.), Impact testing of cermets, progress Rept. No. 2, July 1 to Oct. 1954, Contract No. AF33 (616) 2380 expenditure order No. R-506-67C SR 7 Z to power plant laboratory (WCLPG-5), Wright Air Development Center, Wright-Patterson Air Force Base, Ohio, Chap. VII-Modulus of elasticity P. 52.

[6] T. S. Shevlin, H. W. Newkirk, E. G. Stevens and H. M. Greenhouse, Preliminary microscopic studies of cermets at high temperatures, WADC Technical Rept 54-33 Part 2, The Ohio State University Research Foundation WADC (Feb. 1956).

[7] D. E. Couch, H. Shapiro, J. K. Taylor, and A. Brenner, Protection of molybdenum from oxidation at elevated temperatures J. Elec. Soc. 105, [8] 450 (1958).

[8] S. Spinner and R. C. Valore Jr., Comparison of theoretical and empirical relations between the shear modulus and torsional resonance frequencies for bars of rectangular cross section, J. Research NBS 60, (5) 459 (1958) RP2861.

[9] H. W. Newkirk, Jr. and H. H. Sisler, Determination of residual stresses in titanium carbide base cermets by high temperature X-ray diffraction, J. Am. Ceram. Soc. 41, (3) 93 (1958).

[10] F. A. Mauer and L. H. Bolz, Measurement of thermal expansion of cermet components by high-temperature X-ray diffraction WADC Tech. Rept. 55-473 (Dec. 1955).

[11] F. C. Nix and D. MacNair, Thermal expansion of pure metals: copper, gold, aluminum, nickel, and iron, Phys. Rev. 60, 597 (1941).

[12] S. Spinner, Elastic moduli of glasses at elevated temperatures by a dynamic method, J. Am. Ceram. Soc. 39 [3] $113(1956)$.

[13] G. Pickett, Equations for computing elastic constants from flexural and torsional resonant frequencies of vibration of prisms and cylinders, Am. Soc. Testing Materials 45, 846 (1945). 
[14] W. Koster, Citation from Richard M. Bozorth, Ferromagnetism, P. 693 (D. Van Nostrand Co., Inc., New York, N.Y., 1951).

[15] C. Zener, Elasticity and anelasticity of metals, The University of Chicago Press, Chicago, Ill. (1948).

[16] E. A. Stern, Theory of the anharmonic properties of solids, Phys. Rev. 111786 (1958).

[17] P. Schwartzkopf and R. Kiefer, W. Leszynski, and F. Benesovsky, Refractory hard metals, ch. V, p. 67 The MacMillan Co., New York, N.Y. (1953).

[18] J. K. Mackenzie, The elastic constants of a solid containing spherical holes, Proc. Phys. Soc. (London) 63B (1) p. 2 (1950).
[19] R. L. Coble and W. D. Kingery, Effect of porosity on physical properties of sintered alumina, J. Am. Ceram. Soc. 39 [11] p. 377 (1956).

[20] S. M. Lang and F. P. Knudsen, Some physical properties of high-density thorium dioxide, J. Am. Ceram. Soc. 39 (12) p. 415 (1956). 